\title{
Subcapsular Transplantation of Tissue in the Kidney
}

\author{
Leonard D. Shultz, ${ }^{1,4}$ Neal Goodwin, ${ }^{1}$ Fumihiko Ishikawa, ${ }^{2}$ Vishnu Hosur, ${ }^{1}$ Bonnie L. Lyons, ${ }^{1}$ \\ and Dale L. Greiner ${ }^{3}$ \\ ${ }^{1}$ The Jackson Laboratory, Bar Harbor, Maine 04609; ${ }^{2}$ The Laboratory for Human Disease Models, RIKEN \\ Research Center for Allergy and Immunology, Yokohama, Kanagawa 230-0045, Japan; ${ }^{3}$ University of \\ Massachusetts Medical School, Worcester, Massachusetts 01605
}

MATERIALS

Multiple sites can be used for the engraftment of primary human cells and tissues into murine hosts. For example, leukemias are usually best engrafted intravenously, but they can also be engrafted directly into the bone marrow cavity. Some solid tumors such as colon tumors grow successfully following subcutaneous engraftment, sometimes requiring provision of a Matrigel artificial basement membrane. In certain cases (e.g., human bladder cancer and ductal breast carcinoma), the use of the autochthonous site (bladder and mammary duct, respectively) is often most efficient, whereas the tumors can grow poorly when transplanted subcutaneously or heterochthonously. Here, we present a protocol for the surgical implantation of tissues under the kidney capsule. The kidney is especially suited for the transplantation of normal as well as malignant cells and tissues. It is very accessible, and transplanted tissues are well contained under the renal capsule in a highly vascularized site. Furthermore, the retroperitoneal location of the kidney, together with its separation from other organs, is advantageous both for imaging and biopsy.

It is essential that you consult the appropriate Material Safety Data Sheets and your institution's Environmental Health and Safety Office for proper handling of equipment and hazardous materials used in this protocol.

Reagents
Carprofen
Gelfoam (hemostatic agent)
Isopropyl alcohol (70\%)
Ophthalmic ointment (Puralube)
Saline $(0.9 \%$, sterile $)$
Surgical iodine (10\% solution)

Equipment

Adhesive tape or gauze

Autoclave

Blunt probe (Fine Science Tools 10160-13)

Circulating warm water pad and pump (Gaymar T pump) or other warming device

\footnotetext{
${ }^{4}$ Correspondence: lenny.shultz@jax.org

(C) 2014 Cold Spring Harbor Laboratory Press

Cite this protocol as Cold Spring Harb Protoc; doi:10.1101/pdb.prot078089
} 
L.D. Shultz et al.

Cotton-tipped applicators

Drape (for sterile surgical field)

Extra-fine Graefe forceps, straight, $1 \times 2$ teeth (Fine Science Tools 11153-10)

Fiber-optic illuminator

Fine scissors (sharp; Fine Science Tools 14060-09)

3 French silicone catheter (with a 2 French rounded tip; NorfolkAccess Technologies)

Fur Clipper (\#40 blade)

Graefe forceps (two, curved; Fine Science Tools 11051-10)

Isoflurane anesthesia machine (or injectable general anesthetic)

Laminar flow hood (HEPA-filtered)

Moria iris forceps (curved; Fine Science Tools 11373-12)

Needle (blunt tip)

NSG laboratory mice (e.g., obtained from The Jackson Laboratory; stock number 05557)

Olsen-Hegar needle holders with scissors (Fine Science Tools 12002-12)

Stereomicroscope

Scale

Surgical gloves

Surgical mask

Suture (absorbable, 5-0)

Swab (sterile)

Syringe $(1 \mathrm{~mL})$

Vannas spring scissors, $3 \mathrm{~mm}$ cutting edge (Fine Science Tools 15000-00)

Wound clip (Autoclip; 9 mm kit)

This procedure describes the subcapsular transplantation of tissue on the left kidney. The left kidney is easier to access for surgical procedures because of a more caudal location in the abdomen relative to the right kidney. If bilateral transplantation is required, the same procedure is used on the right kidney.

Aseptic technique is essential for any survival surgery; it requires that all surgical instruments and supplies be sterile. For immunocompromised recipients, such as the NOD-Prkdc ${ }^{\text {scid }} \mid l 2 \mathrm{rg}^{\text {tmiWjl }}$ (NSG) mouse, surgery should be conducted in a HEPA-filtered laminar flow hood to prevent microbial contamination of the surgical site.

\section{Removal of Fur and Preparation of Skin}

1. Anesthetize the mouse and assess it for a surgical plane of anesthesia by the absence of movement to a firm toe pinch.

2. Remove the fur, using fur clippers, from the left flank in an area bounded craniocaudally by the last rib and iliac crest, and dorsoventrally by the spine and lower third of the abdominal wall.

3. Remove loose fur with adhesive tape, dry gauze, or gauze slightly dampened with isopropyl alcohol.

4. Place ophthalmic ointment on the eyes to prevent drying of the cornea and administer carprofen ( $5 \mathrm{mg} / \mathrm{kg}$ ) subcutaneously.

5. Disinfect the skin with surgical iodine and 70\% isopropyl alcohol using sterile swabs. Start by applying 70\% isopropyl alcohol in the center of the proposed incision site and work outward in ever-widening circles to cover the entire clipped area.

6. Using a new sterile swab, apply surgical iodine in the same manner.

7. Repeat $70 \%$ isopropyl alcohol and surgical iodine scrub (Steps 5 and 6) one additional time. 
8. Place the mouse in right lateral recumbency and position a drape over the surgical site.

9. Use straight forceps and fine scissors to make a skin incision $(6-9 \mathrm{~mm})$ parallel and ventral to the spine and midway between the last rib and the iliac crest. (For tissue transplantation under the capsule of the right kidney, make the incision immediately caudal to the last rib.)

10. Make a similar incision in the underlying abdominal wall.

11. Externalize the kidney.

i. Place curved forceps under the caudal pole and gently lift the caudal pole through the abdominal incision.

ii. Reposition the forceps under the cranial pole and gently lift through the incision.

iii. Rotate the kidney slightly such that it is held in place by the abdominal wall. Do not grasp the kidney or renal vessels with the forceps.

12. Make a small incision with Vannas spring scissors in the capsule over the caudal-lateral aspect of the kidney.

The size of the incision depends on the size of the transplanted tissue. Generally, the size of the tissue that is to be transplanted should not exceed approximately one-fifth of the size of the kidney.

13. Keep the kidney moist with warm sterile saline.

14. Transplant the tissue into the murine host using one of the following procedures.

- Make a shallow subcapsular pocket with a blunt probe, and place the transplant tissue into the pocket with iris forceps. Advance the tissue toward the cranial pole of the kidney by placing the forceps on the capsule surface, caudal to the tissue, and gently moving the forceps cranially.

- Draw the cells to be injected up into a $1-\mathrm{mL}$ syringe and deliver them through a blunted 25-gauge needle attached to a silicone catheter. Advance the catheter through the capsule incision to the cranial pole and slowly discharge the cells from the catheter.

See Troubleshooting.

15. Place Gelfoam over the capsule incision.

The incision in the capsule is not routinely closed; however, this Gelfoam prevents backflow of injected cells.

16. Return the kidney to the abdomen.

17. Close the incision in the abdominal wall with a 5-0 absorbable suture with a swaged needle, then close the skin incision with a wound clip.

18. Place the mouse in a clean cage, and let it recover on a circulating warm water pad until ambulatory.

19. Check the mouse daily for normal wound healing, and remove the wound clip in 5-7 d.

Problem (Step 14): Bleeding occurs beneath the kidney capsule.

Solution: This is caused by injury to the kidney beneath the capsule. If clotting is extensive, the capsule will become distended and this can compromise the security of the transplanted tissue. Place Gelfoam over the capsule incision (Step 15) to help retain the transplanted tissue under the capsule. If bleeding is excessive, the mouse should be killed. 
Bankert RB, Balu-Iyer SV, Odunsi K, Shultz LD, Kelleher RJ Jr, Barnas JL, Simpson-Abelson M, Parsons R, Yokota SJ. 2011. Humanized mouse model of ovarian cancer recapitulates patient solid tumor progression, ascites formation, and metastasis. PLoS ONE 6: e24420.

Goldstein AS, Huang J, Guo C, Garraway IP, Witte ON. 2010. Identification of a cell of origin for human prostate cancer. Science 329: 568-571.

Lin T-Y, Li Y-P, Zhang H, Luo J, Goodwin N, Gao T, White R, Lam KS, Pan C-X. 2012. Tumor-targeting multifunctional micelles for imaging and chemotherapy of advanced bladder cancer. Nanomedicine (Lond) 8: 1239-1251.
Pearson T, Greiner DL, Shultz LD. 2008. Creation of "humanized" mice to study human immunity. Curr Protoc Immunol Chapter 15: Unit 15.21. doi: 10.1002/0471142735.im1521s81.

Stewart JM, Shaw PA, Gedye C, Bernardini MQ, Neel BG, Ailles LE. 2011. Phenotypic heterogeneity and instability of human ovarian tumor-initiating cells. Proc Natl Acad Sci 108: 6468-6473.

Valdez KE, Fan F, Smith W, Allred DC, Medina D, Behbod F. 2011. Human primary ductal carcinoma in situ (DCIS) subtype-specific pathology is preserved in a mouse intraductal (MIND) xenograft model. J Pathol 225: 565-573. 


\section{Subcapsular Transplantation of Tissue in the Kidney}

Leonard D. Shultz, Neal Goodwin, Fumihiko Ishikawa, Vishnu Hosur, Bonnie L. Lyons and Dale L. Greiner

Cold Spring Harb Protoc; doi: 10.1101/pdb.prot078089

\begin{tabular}{rc}
\hline $\begin{array}{r}\text { Email Alerting } \\
\text { Service }\end{array}$ & Receive free email alerts when new articles cite this article - click here. \\
\hline $\begin{array}{c}\text { Subject } \\
\text { Categories }\end{array}$ & $\begin{array}{c}\text { Browse articles on similar topics from Cold Spring Harbor Protocols. } \\
\text { Mouse (437 articles) }\end{array}$ \\
\hline
\end{tabular}

